\title{
The Impact of Translators' Epistemological Beliefs and Gender on Their Translation Quality
}

\author{
Elmira Araghizade ${ }^{1,2}$ \& Esmaeil Jadidi ${ }^{2}$ \\ ${ }^{1}$ Department of English, Fars Science and Research Branch, Islamic Azad University, Marvdasht, Iran \\ ${ }^{2}$ Department of English, Marvdasht Branch, Islamic Azad University, Marvdasht, Iran \\ Correspondoncer: Esmaeil Jadidi, Department of English, Marvdasht Branch, Islamic Azad University, \\ Marvdasht, Iran. Tel: 98-917-314-5087. E-mail: esmaeil.jadidi@yahoo.com
}

\author{
Received: January 10, 2016 Accepted: February 26, $2016 \quad$ Online Published: March 1, 2016 \\ doi: 10.5539/elt.v9n4p24 \\ URL: http://dx.doi.org/10.5539/elt.v9n4p24
}

\begin{abstract}
This study aimed to determine the relationship between translators' epistemological beliefs and gender on their Persian-to- English translation quality. To do so, a group of 53 MA translation students both male and female were selected, through convenient sampling to participate in this study. For data collection two instruments were employed: 1- Epistemic Beliefs Inventory (EBI) 2- Translation Test including a piece of poem. Regression analysis was also conducted to explore the interaction of epistemological beliefs and gender of translators on their translation quality. The findings indicated that there is no significant relationship between the components of epistemological beliefs and translation quality, except in one case that QL (quick learning) has a negative relationship with translation scores. Translators' gender significantly affects the translation quality. An implication of the results is that males translate significantly better than females regarding the quality of translation. The interaction of translators' epistemological beliefs and gender significantly affect the translation quality.
\end{abstract}

Keywords: translation quality, epistemological beliefs, gender

\section{Introduction}

"Translation is a kind of communicative, socio-cultural act which involves a network of relations between agents, groups, and individuals and will make the role of the translator like that of a mediator. In this communicative act the translator has the responsibility for selecting the appropriate language, eliminating, modulating, adding, etc". (Shahsavari, 2011, cited in Tadayon, 2015) (p. 4). Different factors can affect translation quality; these factors can be divided into two groups: psychological and demographic factors. Psychological factors refer to translators' beliefs and translators' mental activities and translators' ideology. Demographic factors refer to characteristics such as gender, age (Varzande, 2015). Previous studies indicated that all of these factors in different conditions affect translation quality significantly.

Translators' gender is one of the possible factors which can affect on the ultimate process of translation, and translation accuracy is also of the main and principal features used in the assessment and analysis of every translated text. A huge number of studies have been done in the domain of translation, its characteristics and the effective factors on it. Among them, translators' gender which has a vast considerable reflection on the translation process and production is one of the elements attended and surveyed by many researchers.

Epistemological beliefs refers to the knowledge of knowing, the nature of knowledge and how to conceptualize matters, Therefore Translators' epistemological beliefs may affect his or her way of producing a text so it is of a great importance during the process and product of a translation. According to Kienheus (2010) "epistemology or epistemic beliefs have become a target of increased research interest in developmental and educational psychology". In the following, the term "epistemic beliefs" shall be consistently used to refer to a person's beliefs about the nature of human knowledge, like its certainty and how it is conceptualized, and a person's beliefs about the criteria for and the process of knowing.

Each translator has different epistemological beliefs and these beliefs due to their direct contact to knowing and knowledge may influence his or her translation procedure and translation quality too. So assessing these beliefs plays an important role in the evaluation of the translation. 
There have been many studies about epistemological beliefs and their effects on different courses and fields, but in the domain of translation studies few studies have examined the impacts of epistemological beliefs on translation quality.

As a relatively new research area in the field of translation this study aimed to explore the relationships between translators' epistemological beliefs and translation quality, thus it tries to determine if the translators' epistemological beliefs significantly affect their translation quality. Also, the researcher considered the translators' gender impacts on translation quality to see if there is any relationship between translators' gender and their translation quality.

\section{Review of Literature}

\subsection{Empirical Studies on the Effect of Translators' Gender on Their Translation Quality}

In 2010, Ahmadian investigated the relationship between translators' gender and their translation quality. She studied their different writing styles through translation process.150 BA translation students were requested to participate in this study ( 75 males and 75 females). The sample of this study took a translation task of two English paragraphs (expressive \& informative) to be translated into Persian. The participants were, then, requested to write a paragraph in Persian.The results of the study manifested women who had expressive writing style, outperformed in translating the expressive and those with the informative one, was better in translating the informative text. However, results indicated that due to the slight difference between women's translation quality in the aforementioned texts and their writing style, no significant relationship was observed between the variables of interest.

LotfiKashmar (2013) examined the relationship between gender and theoretical knowledge of translation and practical skills on translation in Iranian translators. The theoretical test, a collocation composed of 30 multiple-choice items adopted from M.A and PhD entrance exam, held in the years 2011, 2012, public and Azad University course in Iran.” The practical exam was their term paper, so they answered carefully. Some parts of these texts were unseen and some others were seen because their proficiency on vocabulary was not important for this test and just the students' proficiency in practical translation was the main point". 35 MA students both males and females were asked to participate in this study. She applied two kinds of test: theoretical and practical. The finding of this study showed that students' practical skill in translation both male and female was better than their theoretical knowledge, but male's theoretical scores were better than females. Based on the results of this study, she concluded, that gender is an important factor on theoretical scores.

\section{Methodology}

This study was a quantitative study. The design of this quantitative study was causal-comparative in nature. In this design, causes were identified as the translators' epistemological beliefs and gender, and their effect on the translation quality remained to be investigated.

\subsection{Participants}

A population of 53 MA translation students of Islamic Azad university of Marvdasht participated in this study. This population consisted of 12 males and 41 females. They were selected by convenient sampling method. The reason for choosing this group of students was that they had passed some courses of translation so they had achieved some skills in translation studies.

\subsection{Instruments}

Two instruments were administered in this study in two ways: 1-group administration 2- email administration. 1EBI (Epistemic Beliefs Inventory) 2- Translation text (literary text).

\subsection{Epistemic Beliefs Inventory}

First there is epistemic beliefs inventory by Schraw, Bendixen, and Dunkle, 2002. The EBI consists of 32 items, for which individuals respond using a 5-point Likert-type rating scale from strongly disagree (1) to strongly agree (5) to items concerning their beliefs about education and learning. The inventory was developed to measure five underlying constructs: Certain Knowledge, Innate Ability, Quick Learning, Simple Knowledge, and Omniscient Authority.

\subsection{Literary Text}

The second instrument which is applied is a part of Mehdi Akhavan Sales poem (a well known Iranian poet) which consists of 81 words. This had been shared among participants to be translated. 


\subsection{Data Collection Procedure}

The epistemic beliefs inventory and the selected text were administered simultaneously and in two ways 1group administration 2- E-mail administration. 100 questionnaires through group administration and 30 through email administration were shared between participants. First 130 questionnaires were given to the population under study, after fourteen days only 53 questionnaires were collected which means 53 students participated in the study by their own choice.

\subsection{Data Analysis Procedure}

The reliability of the epistemic beliefs inventory was calculated by Cronbach's Alpha which is 0.74 . Translation quality was assessed by two experts: the first rater was the researcher herself, who assessed the translated texts according to Waddington's (2001) model of translation and the second rater was a MA student. Then based on two sets of scores obtained from translated texts , using Waddington's model holistic method (method C): This method of Waddington's model is based on three important factors : accuracy of transfer from source to target text, quality of expression in the target language and degree of task completion., the inter-coder reliability was calculated, which was estimated to be 0.86 . The inter coder reliability was assessed by Pearson correlation in order to find how close are the scores of rater 1 and rater 2 . The relationship between epistemological beliefs and translation quality was assessed by correlation coefficient (Pearson) in SPSS statistics. For the second question of study independent T-test SPSS statistics was employed in order to explore the relationships between translators' gender and translation quality. The third question was about the interaction of translators' epistemological beliefs and gender on their translation quality, calculated by Regression analysis in SPSS statistics.

\section{Results}

\subsection{Reliability of Measures}

The reliability of Epistemological Beliefs Questionnaire which was calculated in order to find out how reliable is the questionnaire and how consistent its items are.This reliability estimated to be 0.74. Table 4.1.3 represents the inter coder reliability which was assessed by Pearson correlation in order to find how close are the scores of rater 1 and rater 2, which was estimated to be 0.86 .

Table 1. The results of the correlation between epistemological beliefs and translation scores

\begin{tabular}{|c|c|c|c|c|c|c|c|}
\hline & & $\mathrm{SK}^{\#}$ & CK\# & IA\# & OA\# & QL\# & scorer \\
\hline \multirow[t]{3}{*}{ sk } & Pearson Correlation & 1 & $.364^{*}$ & $.571^{\pi *}$ & $.389^{* *}$ & -0.014 & 0.079 \\
\hline & Sig. (2-tailed) & & 0.011 & 0 & 0.005 & 0.922 & 0.579 \\
\hline & $\mathrm{N}$ & 52 & 48 & 48 & 50 & 51 & 52 \\
\hline \multirow[t]{3}{*}{$\mathrm{ck}$} & Pearson Correlation & $.364^{\circ}$ & 1 & 0.28 & 0.201 & 0.069 & -0.147 \\
\hline & Sig. (2-tailed) & 0.011 & & 0.056 & 0.17 & 0.637 & 0.313 \\
\hline & $\mathrm{N}$ & 48 & 49 & 47 & 48 & 49 & 49 \\
\hline \multirow[t]{3}{*}{ IA } & Pearson Correlation & $.571^{n \pi}$ & 0.28 & 1 & $.356^{\circ}$ & 0.116 & -0.255 \\
\hline & Sig. (2-tailed) & 0 & 0.056 & & 0.013 & 0.429 & 0.077 \\
\hline & $\mathrm{N}$ & 48 & 47 & 49 & 48 & 49 & 49 \\
\hline \multirow[t]{3}{*}{$\mathrm{OA}$} & Pearson Correlation & $.389^{* *}$ & 0.201 & $.356^{*}$ & 1 & 0.229 & -0.053 \\
\hline & Sig. (2-tailed) & 0.005 & 0.17 & 0.013 & & 0.106 & 0.711 \\
\hline & $\mathrm{N}$ & 50 & 48 & 48 & 51 & 51 & 51 \\
\hline \multirow[t]{3}{*}{ QL } & Pearson Correlation & -0.014 & 0.069 & 0.116 & 0.229 & 1 & $-.372^{n-n}$ \\
\hline & Sig. (2-tailed) & 0.922 & 0.637 & 0.429 & 0.106 & & 0.007 \\
\hline & $\mathrm{N}$ & 51 & 49 & 49 & 51 & 52 & 52 \\
\hline \multirow[t]{3}{*}{ scorer } & Pearson Correlation & 0.079 & -0.147 & -0.255 & -0.053 & $-.372^{* *}$ & 1 \\
\hline & Sig. (2-tailed) & 0.579 & 0.313 & 0.077 & 0.711 & 0.007 & \\
\hline & $\mathrm{N}$ & 52 & 49 & 49 & 51 & 52 & 53 \\
\hline
\end{tabular}

*. Correlation is significant at the 0.05 level (2-tailed).

**. Correlation is significant at the 0.01 level (2-tailed). 
SK \#Simple knowledge: indicating subjects' belief that knowledge always can be illustrated in a simple shape.

CK \# Certain Knowledge: indicating subjects' trust in certainty of knowledge.

IA\# Innate ability: indicating subjects' belief that knowledge is connected with innate capabilities.

OA\# Omniscient Authorities indicating subjects' trust in authorities whose opinions are not to be challenged.

QL\#Quick Learning indicating subjects' belief that learning has to occur quickly.

Table 2. Independent samples test between males and females translation scores

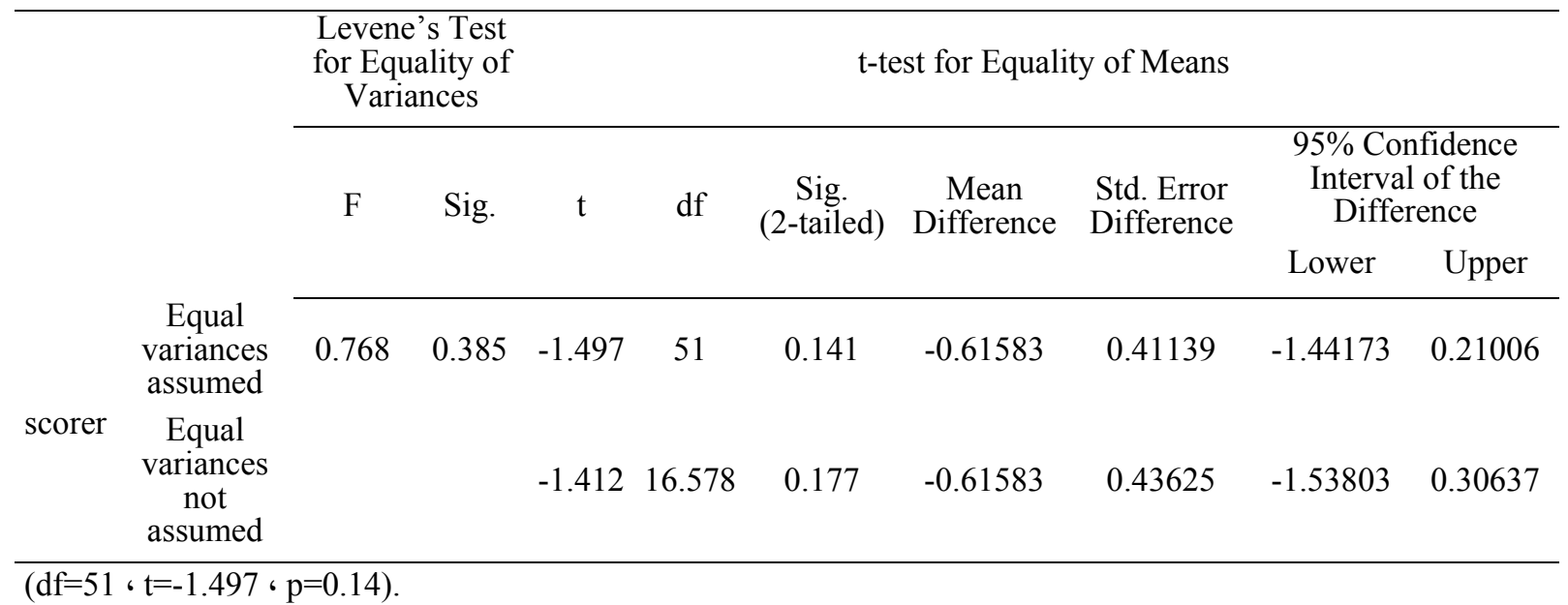

Table 3. Result of regression analysis (interaction of epistemological beliefs and gender role on translation quality)

\begin{tabular}{cccccccccc}
\hline Model & $\mathrm{R}$ & $\begin{array}{c}\mathrm{R} \\
\text { Square }\end{array}$ & $\begin{array}{c}\text { Adjusted R } \\
\text { Square }\end{array}$ & $\begin{array}{c}\text { Std. Error of the } \\
\text { Estimate }\end{array}$ & $\begin{array}{c}\text { R Square } \\
\text { Change }\end{array}$ & $\begin{array}{c}\text { Change Statistics } \\
\text { Change }\end{array}$ & df1 & df2 & $\begin{array}{c}\text { Sig. F } \\
\text { Change }\end{array}$ \\
\hline 1 & $.337^{\mathrm{a}}$ & 0.114 & -0.026 & 0.44024 & 0.114 & 0.814 & 6 & 38 & 0.566 \\
\hline
\end{tabular}

a. Dependent Variable: Gender(F or M):

b. Predictors: (Constant), QL, SK, CK, OA, IA.

Table 4. ANOVA analysis between the interaction of epistemological beliefs and gender on translation quality

\begin{tabular}{ccccccc}
\hline \multicolumn{1}{c}{ Model } & Sum of Squares & $\mathrm{D} \mathrm{f}$ & Mean Square & F & Sig. \\
\hline \multirow{4}{*}{1} & Regression & 0.946 & 6 & 0.158 & 0.814 & $.566^{\mathrm{b}}$ \\
& Residual & 7.365 & 38 & 0.194 & & \\
& Total & 8.311 & 44 & & & \\
\hline
\end{tabular}

a. Dependent Variable: Gender (F or M):

b. Predictors: (Constant), QL, SK, CK, OA, IA.

In Regression Table as it is shown the regression between epistemological beliefs and translation scores was calculated, cause the researcher aimed to find out the impact of epistemological beliefs on translation scores. It was estimated to be 0.01 which is less than 0.05 so the researcher observed no significant relationship between epistemological beliefs and translation scores.

Table 2. presents Independent Samples Test. This analysis was applied in order to find a relationship between Translator's gender and translation scores. According to table 4.1.8 there is a significant relationship between male and female translation scores, $(\mathrm{df}=51 \cdot \mathrm{t}=-1.497, \mathrm{p}=0.14, \mathrm{p}>0.05)$. The researcher claimed that male 
translators translated better than female translators, in other words males translated better and more accurate than females.

In Table 3, regression analysis was calculated in order to find the interaction of epistemological beliefs and gender on translation quality. There is an interaction between epistemological beliefs and gender on translation quality. According to this table, the interaction of epistemological beliefs and gender significantly affect the translation quality.

\section{Discussion and Conclusions}

The first hypothesis was that translators' epistemological beliefs significantly affect translation quality. The findings of the present study revealed that, as mentioned earlier, epistemological beliefs consists of 5 subcategories. These components are certain knowledge (CK), innate ability (IA), quick learning (QL), simple knowledge (SK), omniscient authority (OA).

Among these five, only QL in other words quick learning, affect translation quality, as shown in Table 1, (correlations between epistemic beliefs inventory and translation scores) there isn't any significant relationship between translators' epistemological beliefs and their translation quality, except one case that showed a significant relationship between translators' quick learning(quick learning means that learning has to occur quickly) and their translation scores which was a negative relationship which means if a way of learning gets more quicker the scores of translation will get lower, and there wasn't any significant relationship between other components (CK, SK, OA, IA) of the EBI and scores of translation so the first hypothesis was rejected based on the findings. The researcher claimed that epistemological beliefs did not affect translation quality significantly.

The second hypothesis was that Translators' gender significantly affects the translation quality. The researcher found out that translators' gender affect the translation quality significantly, which proves that males translated better than females (Table 2), so the second hypothesis was accepted. The researcher claimed that translators' gender significantly affect their translation quality, in other words the obtained data indicated that males translators translate better than females translators based on Waddington's model of translation quality assessment.

The third hypothesis was that the interaction of translators' epistemological beliefs and gender significantly affect translation quality. The interaction of epistemological beliefs subcategories and gender on translation quality was conducted; it revealed that the interaction of epistemological beliefs and gender affect translation quality significantly (Table 3 ) and this interaction revealed that the third hypothesis was accepted. In other words with regards to both effects of epistemological beliefs and gender translation quality will be differed.

It was mentioned before that research in the realm of epistemological beliefs and its impact on translation quality has been ignored up to now. Epistemological beliefs have direct relationship with knowledge and knowing so it is one of the factors which may affect the process of translation. The interpretation of the findings of this study is reported based on the previous research. The data provided evidence of a significant relationship between translator's gender and their translation quality. There isn't any significant relationship between translators' epistemological beliefs and their quality of translation (except one of the components QL mentioned earlier), while there is an interaction between epistemological beliefs and gender on translation quality. The interaction of epistemological beliefs and gender significantly affect the translation quality.

\section{Implications of the Study}

The conclusions drawn indicate that translation students should consider the important role of their epistemological beliefs and gender in processing and producing a translation. It is hoped that the findings of the present study will open new horizons for translation students and translation masters and professors, leading to a good awareness of the role of individual differences in the process and product of translation. And shed more lights on these issues affecting translation quality assessment.

\section{Limitations of the Study}

The sample also did not have equal numbers of participants based on gender, most of the subjects of this study are female translation students (41 out of 53). Therefore, the results of the study may not apply to the male population of translation majors.

\section{Suggestions for Further Research}

It is a fact that no research is complete in its own right. The more answers are obtained, the more questions will be raised. The more aspects are considered, the more other aspects will be raised. The domain of translator's epistemological beliefs and its impact on translation quality is too vast to be explored in one single study. Future 
research is definitely needed to shed light on other factors that affect translation quality.

Only literary text is used in this study. Another study may assess different genres of texts in order to assess translation quality.

\section{References}

Ahmadian, M. (2010). The role of gender differences on translation quality. Journal of English Studies and Translation.

Kienhues, D. (2008). Epistemic Beliefs. British Journal of Educational Psychology, 78(4), 545-565. http://dx.doi.org/10.1348/000709907X268589

LotfiKashmar, L. (2013). The Analysis of The Relationship Between Gender, The Theoretical Knowledge of Translators And Their Practical Translation Skills. International journal of learning and applied linguistics world, 3(4), 210.

Shahsavari, Z. (2011). The effect of knowledge of linguistic component of translation component of the source text on the translation quality. Unpublished master's thesis.

Tadayon, S. (2015). A Study of the Relationship between Persian Grammar Knowledge and English into Persian. Translation Quality, 11.

Varzande, M. (2015). The Effect of Translators' Emotional Intelligence on Their Translation Quality. Journal of English Language Teaching, 8(8), 104-111. http://dx.doi.org/10.5539/elt.v8n8p104

Waddington, C. (2001). Different methods of evaluating student translations: The question of validity. Meta, 46(2), 311-325. http://dx.doi.org/10.7202/004583ar

\section{Copyrights}

Copyright for this article is retained by the author(s), with first publication rights granted to the journal.

This is an open-access article distributed under the terms and conditions of the Creative Commons Attribution license (http://creativecommons.org/licenses/by/3.0/). 